\title{
Integrated multitrophic aquaculture business model in Danube area
}

\author{
Gheorghe Adrian Zugravu, Maria Magdalena Turek Rahoveanu, Adrian Turek Rahoveanu, Marian Tiberiu Coada, Stefan \\ Mihai Petrea, Alexandru Cristian Bandi, Mirela Cretu
}

\begin{abstract}
The importance of water for life, as a component of the global ecosystem, is becoming clearer and clearer. Water resources are influenced by many activities such as those belonging to agriculture and industry as well as domestic activities. This paper has contributed to the modeling aquaculture business domain and to improve some of quality indicators of the Danube's corps of water. The aims of this study is to integrate in aquaculture business model the aquaculture production system with agricultural production system (aquaponics) and to reconcile and achieve social, economic and environmental objectives with processing and marketing action to add more value to end aquaponics products.
\end{abstract}

Keywords-aquaculture, aquaponics, water quality, integrated systems, business model.

\section{Introduction}

Aquaculture will continue to play an important role in world production over to meet the growing global demand for products based on fish. There are many ways to group and to describe the various types of freshwater aquaculture

Gheorghe Adrian Zugravu

"Dunărea de Jos" University of Galați

Romania

Maria Magdalena Turek Rahoveanu

"Dunărea de Jos" University of Galaţi

Romania

Adrian Turek Rahoveanu

University of Agronomic Sciences and Veterinary Medicine of Bucharest Romania

Marian Tiberiu Coada

"Dunărea de Jos" University of Galaţi

Romania

Stefan Mihai Petrea

"Dunărea de Jos" University of Galaţi

Romania

Alexandru Cristian Bandi

"Dunărea de Jos" University of Galați

Romania

Mirela Cretu

"Dunărea de Jos" University of Galați

Romania production. But from the point of view of sustainability, production methods can be the most reasonable basis for description. Aquaculture already supplies approximately 50 percent of the fish and seafood consumed worldwide, and production is steadily increasing.

The success of land-based aquaculture in improving fishery production and the quality of product has caused this practice to rapidly grow. There are good tendencies shown by aquaculture practices in many countries. Integrated Multi-Trophic Aquaculture (IMTA) is one solution that encourages greater environmental stewardship while increasing economic benefits for growers and communities. IMTA is a different way of thinking about aquatic food production that is based on the concept of recycling. Integrated aquaculture has two principle objectives: to reduce pollution and to increase productivity.

There is a new concept developed from polyculture called Integrated Multi-trophic Aquaculture (IMTA), which is known as a strategy for reducing environmental load from aquaculture ponds.

This approach is based on Ecosystem-Based Management (EBM) that expects people to maintain environment quality while utilizing the resources on it. IMTA uses biofilters, specific species such as seaweed and oyster, that have the ability to recycle nutrient or load produced by the main species grown (1).

Studies on integrated systems have primarily focused on inland freshwater systems, and only a few have investigated the possibilities of integrated farming in marine systems. In the past two decades, integration of seaweeds with marine fish culture has been examined and studied in Canada, Japan, Chile, New Zealand, and USA (2, 3, 4, 5, 6, 7). The FAO Technical Paper "Integrated mariculture: a global review" $(8,9,10)$ reviewed integrated systems in the latter areas, but there almost no information on Chinese systems was probably due to limited availability of accurate information (11). In China, integration of cultures is a common practice for inland production systems, while integrated mariculture is a recent development expanding at a fast rate. It is essential for sustainable development of mariculture to define ecological rationales and draw lessons from various integrated culture techniques in inland waters. Furthermore, for further development of integrated production systems in the coastal zones of China it is important to show its effectiveness in comparison to monocultures. Such a comparison should include production and economic revenues on one side, and environmental benefits on the other side. 
Parallel to aquaculture industry development, knowledge of its effects on the surrounding environment is increasing. Several studies have been conducted to assess the environmental impact $(12,13)$ due to aquaculture. Organic enrichment is recognized as the most important problem associated to aquaculture $(14,3)$ as a direct result of the release of dissolved and particulate nutrient loads, especially organic phosphorous and nitrogen in the form of ammonia that might easily induce eutrophication (15). Uneaten pellet and fresh food supplied at fish cages, together with the excretion products from cultured fishes are the source of the nutrient loads released (16).

The growing concern on aquaculture's environmental impact has led to an increasing research into feed formulations and digestibility, better conversion efficiency and improved management $(17,3)$. Since the last decade, the emphasis has been placed on the practice of integrated multi-trophic aquaculture (IMTA), with a potential to mitigate some of the environmental problems associated with mono-specific aquaculture (10). Originally used in freshwater practices, it involves the culture of two or more species from different trophic level; generally finfish being simultaneously cultured with both organic and inorganic extractive species, such as shellfish and seaweeds, respectively; in which by-products from one species are recycled to become inputs for another. Thus, the organic matter released in aquaculture systems might represent a source of available food for filter-feeding organisms, such as bivalves, reducing its impact on the environment (18) and can represent a potential economic income.

Filter feeders bivalves are essentially generalist consumers, and it has been demonstrated that they can exploit organic matter from several sources, as a function of its availability (19). In a conceptual open water integrated aquaculture, filter feeder bivalves are cultured adjacent to fish floating cages, reducing nutrient loadings by filtering and assimilating particulate wastes (uneaten food and faeces) as well as phytoplankton. In this way, bivalves would perform as biological filters. Previous studies have determined that bivalves can be successfully incorporated into integrated multitrophic aquaculture systems, based on the increased growth displayed and the feeding efficiency on pellet feed and fecal products $(20,21)$.

IMTA has been proposed for mitigating aquaculture waste release, and has advantages that may include a reduced ecological footprint, economic diversification and increased social acceptability of culturing systems. IMTA has the promise to contribute to the sustainability of aquaculture. However, most studies have focused on landbased systems, and only a few have to-date investigated the possibilities of IMTA farming in open water. In the past fifteen years, the integration of seaweeds with marine fish culturing has been examined and studied in Canada, Japan, Chile, New Zealand, and USA (2, 3, 4, 5, 6, 7). IMTA have been commercially successful at industrial scales in China for many years.

\section{Materials and Methods}

The methodology for assessment of the model of multiuse aquaponics production platforms entails the following general steps:
The socio-economic characterization of the model of multi-use aquaponics production platforms in terms of agriculture, aquaculture and social services.

- The production and demand structures of the proposed model of multi-use aquaponics production platforms are investigated. This is done by the identification and quantification of costs and benefits of suggested multi-use aquaponics production platforms by using market and nonmarket methods in order to capture private, social and ecological effects.

- Policy recommendations are based on economic tools such as Cost-Effectiveness Analysis, CostBenefit Analysis and other approaches to socioeconomic analysis such as Multi-Criteria Decision Analysis.

The suggested methodology for socio-economic analysis consists of a baseline profiling of case and socioeconomic characterization with regard to future economic activities (agriculture production, aquaculture and social services). Then, production and demand functions of the model of multi-use aquaponics production platforms are identified. A decision on whether full or limited data should be collected for an impact assessment is taken. Thereafter data on the site is collected and costs and benefits are quantified. The assessment of impacts and evaluation of the assessment based on limited data approach, integrating results on Impact Assessment Analysis are conducted. Finally, policy recommendations based on impact assessment results and sensitivity analysis are provided.

This part of the framework focuses on gathering information about the socio-economic environment and context of the proposed development with regard to aquaponic production, aquaculture and social services. Hence, before achieving the evaluation of the socioeconomic impact it is necessary to start with the baseline profiling of the case study areas in order to identify who is going to be impacted. Thus, this approach is expected to enable the identification of the production and demand functions of the model of multi-use aquaponics production platforms.

In order to assess indirect and induced impacts a regional profiling is necessary. The information typically gathered as part of a regional profile includes the population characteristics, the political and social resources, a description of historical factors, identification of the relationships with the biophysical environment, culture, attitudes and social-psychological conditions, the current status of operations (aquaculture, aquaponic production, social services) and the identification of the people who will be impacted by the project (22). The initial assessment must include economic and social analysis of the use of waste waters under current use and future autonomous developments. This assessment should include both market and non-market costs and benefits. The scope is the profiling of all current uses and identifying businesses, households and individuals that may be impacted by the future installation of the model of multi-use aquaponics production platforms. Furthermore, broader social and environmental issues related to current and future operations should be highlighted. 
The following subsections identify economic issues, environmental issues and social issues concerning level of employment, regional development and overall attitude of the population towards the technologies and specific options proposed. The production and demand analysis is based on economic data, environmental valuation surveys and Benefit Transfer techniques.

This analysis is based on proposed financial costs of the model of multi-use aquaponics production platforms structures as well as social and environmental costs. The identification of the private costs of the suggested model of multi-use aquaponics production platforms structures with regard to aquaculture and social services is the first step of the production-side analysis. Training costs are expected to cover the training of people who will run the platforms with regard to the safety, financial and environmental implications of the project.

Since the scope of the developed methodology is to integrate private, social environmental costs of the suggested model of multi-use aquaponics production platforms it is equally important to consider the latter in the suggested framework of analysis.

The analysis here is focused on proposed financial, social and environment benefits of the platform structures.

\section{Results and Discussions}

IMTA involves cultivating organisms in a way that allows the uneaten feed, wastes, nutrients and by-products of one species to be recaptured and converted into fertilizer, feed and energy for the growth of the other species. IMTA farmers combine species that need supplemental feed such as fish, with "extractive" species.

Essentially, extractive species act as living filters. The natural ability of these species to recycle the nutrients (or wastes) that are present in and around fish farms can help growers improve the environmental performance of their aquaculture sites. In addition to their recycling abilities, the extractive species chosen for an IMTA site are also selected for their value as marketable products, providing extra economic benefits to farmers.

Sustainability of aquaculture not only requires that it has a neutral effect on the environment but also that it be economically feasible. A further condition is that of social acceptability; that attitudes towards the sector are at least neutral.

Economic analyses will have to recognize and account for the values of the environmental/societal services of extractive crops to estimate the true value of these IMTA components. They will have to include the impacts of organic and other ecolabelings, the value of biomitigating services for enhanced ecosystem resilience, the savings due to multi-trophic conversion of feed and energy that would otherwise be lost, and the reduction of risks through crop diversification and increased societal acceptability. This would create economic incentives to encourage aquaculturists to further develop and implement sustainable marine agronomy practices such as IMTA.

The future development of Integrated Multi Trophic Aquaculture (IMTA) will depend on both how financially profitable it is for farmers and how it is regulated. From the perspective of farmers, IMTA offers a number of potential economic advantages in comparison with non IMTA, including increased physical production from a given site, greater diversity of production, and more intensive use of facilities, labor and sites. These must be balanced against potential economics disadvantages such as greater complexity, more risks, and greater challenges in site selection. From a public perspective, IMTA offers significant potential public benefits in comparison with non IMTA, including reduced negative environmental impacts and positive ecosystem services. Although methodologies exist to estimate the economic value of these benefits, they can be expensive and imprecise.

The synergistic cultivation and rearing of plants and animals is an ancient practice and continues to be used for extensive food production in many parts of the world. However, the intensification of terrestrial and aquatic food production-the so-called green and blue revolution, respectively-has been characterized by a monocultural approach along with the partitioning of feed, fertilizer, and food production components. The recognition of significant and deleterious environmental effects of this intensive and industrialized food production approach has led to a more recent reexamination and application of traditional practices of integrating multiple trophic levels in terrestrial and aquatic systems.

There was strong concurrence on five factors listed under this topic (that is, factors with value sums of midrange or higher). In the area of strengths, the respondents agreed strongly on the importance of a benefit or service to the environment that could be provided by IMTA (nutrient recycling especially in closed systems). Strong concurrence on one weakness qualified the enthusiasm for the environmental service that had been seen as a strength, by pointing to the lack of thorough understanding of environmental impacts of IMTA. The threats upon which the respondent group agreed most strongly were not directly in the area of ecology, but rather expressed concern about the economic feasibility of IMTA, and the impact that environmental issues could have on the necessary social license to operate (potentially lower profitability compared to existing aquaculture systems; not enough public funding for developing a network of demonstration and research sites to examine the feasibility of IMTA; and larger scale applications may have greater environmental impact and thus less social license).

The weaknesses have to do most importantly with the complexity of IMTA (complexity: marketing, operations, juveniles, business planning; and regulatory complexity), and that the economic threats would be lack of social acceptance/public perception; susceptibility to natural hazards (disease, parasites, storms), and greater regulatory requirements for IMTA.

Strengths of IMTA that could help move aquaculture forward appear to be that it is a new approach that could be more acceptable to the general public and to local communities because it can supply environmental services to clean up environmental contaminants where it is practiced in open systems, and can in closed, recirculation systems isolate cultured species and potential contaminants, diseases, etc., from the natural environment. There is a positive perception of the sustainability of IMTA systems, and of its ability to use alternative feeds rather than those made 
entirely from fish. Further, there would be economic advantages from the multiple products that can be sold in new market areas, including niche markets, and IMTA would open many opportunities for research, innovation, partnerships, and education.

Strengths and opportunities are manifold. Concerns seem to center on IMTA's complexity at various levels-for example, conceptual, including the difficulty of explaining it to the public and to regulators; and operational, including extra costs for setup, construction, and maintenance; and regulatory, such as in policy, funding, and licensing issues. There is a concern that there is not adequate funding to expand current demonstration efforts, or to expand to new demonstration sites to carry research results forward into practical, commercial-scale application.

Even if aquaculture in the form of IMTA is technically, environmentally, and economically viable, it will not be successful unless it is accepted by society in general, and by the local community and other stakeholders in particular, based on their beliefs, perceptions, and opinions. They must be convinced that IMTA has value and a positive role to play, and that the business is a part of the community, rather than an intruder or burden to it.

Ecosystem approach to aquaculture is a strategy for the integration of the farming activity within the wider ecosystem in such a way that it promotes sustainable development, equity and resilience of interlinked social and ecological systems (10). Integrated farming is one of the best paradigms of ecosystem approach to aquaculture with advantages of increment of carrying capacity, bioremediation, diversified products, and prevention of diseases.

Aquaculture developments raise issues of concern in terms of environmental impacts and ecosystem health. For aquaculture systems to be sustainable, they should not cause damage to natural systems by critically increasing (e.g. nutrients) or decreasing the concentrations of natural substances (e.g. chlorophyll). Other potential impacts relate to increasing concentration of man-made substances, such as persistent chemicals and through physical disturbance leading to habitat changes.

Aquaponics is a food production system that combines soil-less vegetable growing (hydroponics) and fish farming (aquaculture) within a closed re-circulating system. This combination of food production methods (hydroponics and aquaculture) removes the problems associated with the individual production methods.

For aquaculture, the main problem with Recirculating Aquaculture Systems is the production of Nitrate rich waste water that must be treated or dumped, creating major environmental problems. For hydroponics, the main problem is the complete reliance on chemical fertilizers to grow the vegetables.

When both methods are combined in an aquaponic unit, the nutrient-rich wastewater from the fish tanks, which would normally need to be treated or dumped, is used as an organic fertilizer for plant production. In turn, this removes the need for chemical fertilizers for plant growth using hydroponics.

The main benefices of aquaponics:

1. Two agricultural products can be produced from only one input (fish food)
2. High density crop production is possible as no real competition for nutrients among the plants

3. Aquaponic food production is very water-efficient (units use less than $20 \%$ of the water needed for normal soil farming) and units can be installed in urban or peri-urban environments

4. Aquaponic food production creates zero waste and no chemical fertilizers or pesticides are used making it a very environmentally friendly method of producing food

Advantages for aquaponic food production:

- Uses organic waste as the plant fertilizer

- Uses natural pest controls

- Tends to produce better tasting and at times more nutritional crops

- Potential for year-round production if growing environment can

be controlled (i.e. greenhouse)

- Imitates a natural eco-system thus making it a highly sustainable

food production method

- Increasing population \& Urbanization

- Declining land agricultural productivity

- Increasing demand for healthy, pesticide free produce

It is considered that the model multi-use aquaponics production platforms have socio-economic and environmental impacts on aquaculture, recreational fishing, yachting and boating and other water-based activities. They also have an impact on land-based activities, agricultural tourism, water waste management, regional employment (direct and indirect) and training opportunities.

The ecosystem services approach can be employed in order to perform the socioeconomic analysis and integrate environmental impacts. Ecosystem services are defined as services provided by ecosystem services approach the natural environment that benefits human welfare.

The ecosystem services approach establishes an environmental baseline, identifies and provides a qualitative assessment of the potential impacts of policy options on ecosystem services and quantifies the impacts of policy options on specific ecosystem services. Finally, the ecosystem services approach assesses the effects on human welfare and values the changes in ecosystem services. When assessing the impact of ecosystem services on human welfare, it is critical to focus on the benefits generated by these services, as this is what affects human welfare directly. It is, therefore, the benefits rather than the services per se that are valued.

Due to the multidimensional character of the impacts leading to welfare gains and sometimes losses, a range of different information is needed in order to assess them. Thus, market data, secondary data for the performance of simulations, survey based primary data, data provided from literature review, consultation with experts and stakeholders and information coming from environmental impact assessments is all deemed as very important in the framework of integrated environmental and socio-economic assessment.

The tremendous impact of aquaponic in aquaculture has been particularly obvious in recent years. However, aquaponic needs to overcome a lack in standardization of methodologies and procedures. 


\section{Conclusions}

The conversion of conventional aquaculture farms in sustainable and ecologically aquaculture farms help aquaculture businesses to achieve economic viability and competitiveness. Green aquaculture is undoubtedly the management technique that has most contributed to support aquaculture businesses to adopt aqua-environmental measures for protection of the environment, natural resources and landscape. Private and financial benefits of suggested model of multi-use aquaponics production platforms could result from the sale of vegetable, aquaculture products and services. Additional benefits could be derived from saving of fuel consumption and reduction of energy expenditure or by product sales (or displaced costs), greater productivity (macro scale) and higher real disposable income (macro scale). Environmental benefits include: mitigated global warming, avoided emissions compared, improved water quality.

\section{Acknowledgment}

Project H2020-MSCA-RISE-2014 No. 645691: Researches on the potential conversion of conventional fish farms into organic by establishing a model and good practice guide.

\section{References}

[1] Lander, T. R., Shaw, R. K., Robinson, S. M. C., \& Martin, J. D. (2009). Blue Mussel (Mytilus edulis) settlement patterns on antifoulant treated salmon nets and its implication for recycling used salmon nets for mussel spat collection in integrated Multi-trophic Aquaculture (IMTA). Canadian Technical Report Fisheries and Aquatic Science (2849).

[2] Buschmann, A., et al., Opportunities and challenges for the development of an integrated seaweed-based aquaculture activity in Chile: determining the physiological capabilities of \&lt;i\&gt;Macrocystis\&lt;/i\&gt; and \&lt;i\&gt;Gracilaria\&lt;/i\&gt; as biofilters. Journal of Applied Phycology, 2008. p. 571-577.

[3] Troell, M.; Halling, C.; Neori, A.; Chopin, T.; Buschmann, A. H.; Kautsky, N. \& Yarish, C. (2003). Integrated mariculture: asking the right questions. Aquaculture, Vol. 226, No. 1-4, (October 2003), pp. 69-90, 00448486

[4] Chopin., T., et al., The AquaNet integrated multi-trophic aquaculture project: Rationale of the project and development of kelp cul tivation as the in organic extractive component of the system. Proceedings of the Integrated Multi-Trophic Aquaculture Workshop 2004: p. 11

[5] Chopin, T., et al., Integrating seaweeds into marine aquaculture systems: A key toward sustainability. Journal of Phycology, 2001. p. 975-986.

[6] Chopin, T., Robinson, S.M.C., Troell, M., Neori, A., Buschmann, A.H., Fang, J., 2008. Multitrophic integration for sustainable marine aquaculture. In: Jørgensen, S.E., Fath, B.D. (Eds.), Ecological Engineering. Vol. [3] of Encyclopedia of Ecology, vol. 5. Elsevier,

[7] Abreu, M.H., et al., Traditional vs. Integrated Multi-Trophic Aquaculture of Gracilaria chilensis C. J. Bird, J. McLachlan \& E. C. Oliveira: Productivity and physiological performance. Aquaculture, 2009. p. 211-220.

[8] Soto, D., Integrated Mariculture - A global review, in FAO Fisheries and Aquaculture Technical PaperPAPER. 2010, FAO: Rome.

[9] Soto, D. and F. Jara, Using Natural Ecosystem Services to Diminish Salmon-Farming Footprints in Southern Chile, in Ecological and Genetic Implications of Aquaculture Activities, T.M. Bert, Editor. 2007, Springer Netherlands. p. 459-475.

[10] Soto, D.; Aguilar-Manjarrez, J.; Bermúdez, J.; Brugère, C.; Angel, D.; Bailey, C.; Black, K.; Edwards, P.; Costa-Pierce, B.; Chopin, T.; Deudero, S.; Freeman, S.; Hambrey, J.; Hishamunda, N.; Knowler, D.; Silvert, W.; Marba, N.; Mathe, S.; Norambuena, R.; Simard, F.;
Tett, P.; Troell, M. \& Wainberg, A. (2008). Applying an ecosystembased approach to aquaculture: principles, scales and some management measures. In: FAO Fisheries and Aquaculture Proceedings 11, FAO.

[11] Troell, M., Robertson-Andersson, D., Anderson, R.J., Bolton, J.J., Maneveldt, G., Halling, C., Probyn, T., 2006. Abalone farming in South Africa: an overview with perspectives on kelp resources, abalone feed, potential for on-farm seaweed production and socioeconomic importance. Aquaculture 257, 266-281.

[12] Holmer, M.; Argyrou, M.; Dalsgaard, T.; Danovaro, R.; Diaz-Almela, E.; Duarte, C.; Frederiksen, M.; Grau, A.; Karakassis, I.; Marbá, N.; Mirto, S.; Pérez, M.; Pusceddu, A. \& Tsapakis, M. (2008). Effects of fish farm waste on Posidonia oceanica meadows: Synthesis and provision of monitoring and management tools. Marine Pollution Bulletin, Vol. 56, No. 9, (September 2008), pp. 1618-1629, 0025326X

[13] Vizzini, S. \& Mazzola, A. (2004). Stable isotope evidence for the environmental impact of a land-based fish farm in the western Mediterranean. Marine Pollution Bulletin, Vol. 49, No. 1-2, (July 2004), pp. 61-70, 0025326X

[14] Mirto, S.; Bianchelli, S.; Gambi, C.; Krzelj, M. K.; Pusceddu, A.; Mariaspina, S.; Holmer, M. \& Danovaro, R. (2010). Fish-farm impact on metazoan meiofauna in the Integrated Multitrophic Aquaculture: Filter Feeders Bivalves as Efficient Reducers of Wastes Derived from Coastal Aquaculture Assessed with Stable Isotope Analyses Mediterranean Sea: analysis of regional vs. habitat effects. Marine Environmental Research, Vol. 69, No. 1, (February 2010), pp. 38-47, 01411136

[15] Karakassis, I. \& Hatziyanni, E. (2000). Benthic disturbance due to fish farming analyzed under different levels of taxonomic resolution. Marine Ecology Progress Series, Vol. 203, (September 2000), pp. 247-253, 01718630

[16] Cheshuk, B.W.; Purser, G.J. \& Quintana, R. (2003). Integrated openwater mussel (Mytilus planulatus) and Atlantic salmon (Salmo salar) culture in Tasmania, Australia. Aquaculture, Vol. 218, No. 1-4, (March 2003), pp. 257-378, 00448486

[17] Skalli, A.; Hidalgo, M. C.; Abellán, E.; Arizcun, M. \& Cardenete, G. (2004). Effects of the dietary protein/lipid ratio on growth and nutrient utilization in common dentex (Dentex dentex L.) at different growth stages. Aquaculture, Vol. 235, No. 1-4, (June 2004), pp. 1-11, 00448486

[18] Shpigel, M. \& Blaylock, R. A.(1991). The Pacific oyster, Crassostrea gigas, as a biological filter for a marine fish aquaculture pond. Aquaculture, Vol. 92, No. 2-3, (1991), pp. 187-197, 00448486

[19] Stirling, H. \& Okumus, I. (1995). Growth and production of mussels (Mytilus edulis) suspended at salmon cages and shellfish farms in two Scottish sea lochs. Aquaculture, Vol. 134, (July 2005), pp. 193-210

[20] Mazzola, A. \& Sará, G. (2001).The effect of fish farming organic waste on food availability for bivalve molluscs (Gaeta Gulf, Central Tyrrhenian, Med): Stable carbon isotopic analysis. Aquaculture, Vol. 192, No. 2-4 (January 2001), pp. 361-79, 00448486

[21] Reid, G. K.; Liutkus, M.; Bennett, A.; Robinson, S. M. C. \& MacDonald, B. (2010). Absorption efficiency of blue mussels (Mytilus edulis and M. trossulus) feeding on Atlantic salmon (Salmo salar) feed and fecal particulates: Implications for integrated multitrophic aquaculture. Aquaculture, Vol. 299, No. 1-4, (February 2010), pp. 165-169

[22] Social Sciences Program, Bureau of Rural Sciences, Department of Agriculture, Fisheries and Forestry, Bureau of Transport and Regional Economics and Australian Bureau of Agricultural and Resource Economics, 2005. Socio-economic Impact Assessment Toolkit: A guide to assessing the socio-economic impacts of Marine Protected Areas in Australia. Prepared for the Australian Government Department of the Environment and Heritage. 